\title{
The Importance of Monitoring Sleep within Adolescent Athletes: Athletic, Academic, and Health Considerations
}

\author{
Lee Taylor ${ }^{1 *}$, Bryna C. R. Chrismas ${ }^{2}$, Ben Dascombe ${ }^{3}$, Karim Chamari ${ }^{1}$ and \\ Peter M. Fowler ${ }^{1}$ \\ ${ }^{1}$ Athlete Health and Performance Research Centre, ASPETAR, Qatar Orthopedic and Sports Medicine Hospital, Doha, Qatar, \\ ${ }^{2}$ Sport Science Program, College of Arts and Sciences, Qatar University, Doha, Qatar, ${ }^{3}$ Department of Rehabilitation, \\ Nutrition and Sport, School of Allied Health, LaTrobe University, Melbourne, VIC, Australia
}

Keywords: sleep disturbance, youth athlete, performance, adaptation, development

Sport academies are the vehicle by which clubs and governing bodies often develop and nurture talented sports people, with their demographic predominately adolescent. Conceptualized initially within Western mass participation sports, academies are now seen across the globe, with a diversity of nationalities, ethnicities, religions, and cultures, encompassing a broad variety of sports.

Substantial prospective capital investment is typically required by academies, balanced by

OPEN ACCESS

Edited by:

Vincent Pialoux,

University Lyon 1, France

Reviewed by:

Shona Halson,

Australian Institute of Sport, Australia

${ }^{*}$ Correspondence:

Lee Taylor

lee.taylor@aspetar.com

Specialty section:

This article was submitted to

Exercise Physiology,

a section of the journal

Frontiers in Physiology

Received: 19 January 2016 Accepted: 02 March 2016 Published: 18 March 2016

Citation:

Taylor L, Chrismas BCR

Dascombe B, Chamari K and Fowler PM (2016) The Importance of Monitoring Sleep within Adolescent

Athletes: Athletic, Academic, and Health Considerations.

Front. Physiol. 7:101

doi: 10.3389/fphys.2016.00101 potential future "on-field" (e.g., Olympic Gold Medal, League Champions, etc) and/or "financial" reward (e.g., transfer fee received for a soccer academy graduate). To contextualize, a successful English Premier League soccer academy runs at a cost of $\sim £ 2.3(\sim \$ 3.3)$ million per year and has produced graduates worth $<£ 100(>\$ 143)$ million since inception, with several players representing their senior national team. The small probability of success within this paradigm, which is mirrored to varying degrees within other sports, has led to a change of ethos within academies. Early academies suffered social and political pressure due to low salaries and "token" educational offerings. Emphasis is now placed on genuine academic and athletic development, in an attempt to ensure that if a successful athletic career is not realized, then employment prospects away from an athletic career are viable. For example, the alignment between the American scholarship system and National Collegiate Athletic Association (NCAA) is well established, with talented athletes attaining full academic scholarships and pursuing Degree level qualifications, with the added prospect of signing professional sport contracts post-graduation, or occasionally during their studies.

Consequently there is increasing competiveness, professionalism, training, and fixture congestion within youth sport, with many suggesting that adolescent athlete rest and recovery is compromised as a result (Bergeron et al., 2015). Worryingly, some youth athletes are now being treated as "commodities" and hence the International Olympic Committee (IOC), amongst others, has called for more diligence to safeguard their psycho-physiological development (Bergeron et al., 2015; Lloyd et al., 2015a,b; Mountjoy and Bergeron, 2015; Mountjoy et al., 2015). The maintenance of appropriate rest, particularly sleep for adolescent athletes was discussed within the recent IOC consensus statement, which stated the need to "design youth athlete development programmes ... to mitigate the risk of overuse injuries and other health problems ... providing sufficient and regular rest and recovery, to encourage positive adaptations and progressive athletic development" (Bergeron et al., 2015).

The importance of sleep for optimal athletic performance and recovery, cognitive/academic performance, and well-being, together with, reducing injury and illness risk within athletes, 
including adolescents, has been consistently purported recently (Luke et al., 2011; Milewski et al., 2014; Owens J. et al., 2014; Baert et al., 2015; Bergeron et al., 2015; Diaz-Morales and Escribano, 2015; Fullagar H. H. et al., 2015; Fullagar H. H. K. et al., 2015; Nedelec et al., 2015a; Prather et al., 2015; Thun et al., 2015). These academic, health and performance agendas are central to the modern academy ethos. However, evidence based practices that practitioners and athletes could utilize to maintain sufficient sleep are limited (Halson, 2014, 2015; Fullagar H. H. et al., 2015; Fullagar H. H. K. et al., 2015; Nedelec et al., 2015a,b), especially within adolescent athletes.

Academy athletes regularly undergo extensive physiological monitoring and sport-specific performance testing (Armstrong and McManus, 2011; Barker and Armstrong, 2011). However, given the suggested positive effects of sufficient sleep and its maintenance on several aspects of athletic performance and recovery (Fullagar H. H. et al., 2015; Fullagar H. H. K. et al., 2015), sleep monitoring is not presently given equal importance and attention compared to "typical" physiological capacity testing (e.g., $\dot{\mathrm{V}}_{2 \max }$ ). Although attempts were made as early 1966 to examine sleep in athletes (Baekeland and Lasky, 1966), sleep monitoring per se within athletes is in its infancy, as is its translation to practice, particularly within adolescent athletes. This is concerning given the susceptibility (Bartel et al., 2015) and incidence of adolescents adopting poor sleep practices and/or suffering disturbed sleep, intentionally or otherwise (Gradisar et al., 2011).

Whilst multi-faceted, and in this opinion article contextualized within a youth athlete paradigm, it is not surprising adolescents suffer sleep disturbances. With advancing adolescence, both positive and negative (e.g., increased nightly screen time, social jet lag, etc.) behaviors develop, which can alter the internal "body clock." One such alteration is to endogenous melatonin nadirs and zeniths, which can perpetuate delayed sleep phase disorder (DSPD; Eckerberg et al., 2012). Compounding this there is often a lack of synchronization between adolescent sleep-wake cycles (retiring later and rising later, i.e., DSPD) and other age categories, with academic (Escribano et al., 2012; Tonetti et al., 2015) and athletic performance (Carskadon, 2005; Facer-Childs and Brandstaetter, 2015; Thun et al., 2015) known to be chronotype sensitive. Talented adolescent academy athletes are predominately coached within a formalized and timetabled environment. This often involves evening training and matches (with long commutes common), followed by early educational classes with rigid start times (Wolfson et al., 2007; Short et al., 2013; Franckle et al., 2015) the next day. As a result, sub-optimal variation of their biologically preferred sleep-wake cycles can occur (Crowley et al., 2007; Owens J. A. et al., 2014; Hirshkowitz et al., 2015). Adolescents, relative to children and adults, have greater variability in sleep between week days (school, or traditional work days) compared to the weekend, with significantly less sleep on the former (Merdad et al., 2014) facilitating accumulative week day sleep debt (Van Dongen et al., 2003a,b). This training and education induced sleep deficit, coupled with social jet lag (see Touitou, 2013; Rutters et al., 2014; Diaz-Morales and Escribano, 2015; for explanation of concept), is concerning from an athletic/academic performance development perspective. Empirical evidence demonstrates that reduced sleep negatively influences athletic/academic performance and various indices of morbidity. Specifically, reduced and/or disturbed sleep has been shown to negatively influence aerobic (Oliver et al., 2009) and anaerobic performance metrics (Bulbulian et al., 1996; Souissi et al., 2003, 2008, 2013; Skein et al., 2013), increase injury and illness risk (Luke et al., 2011; Milewski et al., 2014) whilst affecting team sport match outcome (Smith et al., 2013). Academically, sleep extension by a single standard deviation led to an increase of $4.85 \%$ point in coursework marks in adolescents (Baert et al., 2015) whilst adolescents with insufficient sleep (i.e., DSPD, etc.) have reduced academic achievement and development compared to those with appropriate sleep (Escribano et al., 2012; Diaz-Morales and Escribano, 2015; Sivertsen et al., 2015). Those adolescents with insufficient sleep also increase their risk of various negative health indices and behaviors including, but not limited to; depression, suicidal ideation, anxiety, hyperarousal, increased obesity risk, decreased mental resilience, poor dietary intake, and higher incidences of attention deficit hyperactivity disorder (Kaneita et al., 2007; Nyer et al., 2013; Owens J. et al., 2014; Alibhai et al., 2015; Franckle et al., 2015; Sivertsen et al., 2015). Interestingly within a sample of 287 monozygotic twins, those who slept less exhibited lower levels of self-control and more depressive mental health symptoms (Barnes and Meldrum, 2015) despite identical genetics and shared environmental influences. Thus chronotype and/or sleep disturbances, even between genetically identical individuals with shared environmental influences, can alter a range of academic (Escribano et al., 2012; Diaz-Morales and Escribano, 2015; Tonetti et al., 2015), physical performance (Fullagar H. H. et al., 2015), and mental health indices (Kaneita et al., 2007; Nyer et al., 2013; Owens J. et al., 2014; Sivertsen et al., 2015). Such changes can occur either acutely and/or chronically in adolescents, which warrants the monitoring of sleep behaviors in such a population (Shochat et al., 2014).

Psychological overload and resultant heightened anxiety has been reported within youth athletes, which may stem from, at least in part, non-achievable expectations and demands (Malina, 2010; DiFiori et al., 2014) which may in some instances be parent derived (Harwood and Knight, 2009). Anxiety is acknowledged as a central, albeit multi-faceted factor relative to disturbed sleep within adolescents, the general population, and athletes (Staner, 2003; Papadimitriou and Linkowski, 2005; Mellman, 2006; Juliff et al., 2015; Lastella et al., 2015a,b; Romyn et al., 2016). However, whether anxiety induces sleep disturbance or sleep disturbances result in heightened existing anxiety and/or reduced resilience to anxiety, demonstrates individualization within and between the aforementioned populations. Parallel to this, sleep medication use (with and without prescription) within adolescents is of medical concern, with notable ethnic, gender, mental health, academic, and socio-economic predisposing factors present (McCabe et al., 2011; McCabe and West, 2014; Rigg and Ford, 2014; Boyd et al., 2015; Diaz-Morales and Escribano, 2015; Liakoni et al., 2015; Grandner et al., 2016). Data indicates a $\sim 25 \%$ incidence of medication misuse within adolescents from at least one of the following medication classes; pain, 
stimulant, sleeping, and anti-anxiety (McCabe et al., 2011). Specific to adolescent athletes, a report from the NCAA revealed that $10.3 \%$ of miscellaneous substance abuse was accounted for by sleep medication, with sport-specific differences present (Taylor et al., 2016). For example, $18.2 \%$ of male swimmers (the highest within the report) used such medication (Rexroat, 2014). Therefore, aside from an academic and athletic development perspective, monitoring of academy athletes sleep, and associated behaviors, requires consideration from guardian, pastoral, and ethical perspectives (e.g., medication use, mental health, other non-desirable behaviors, and traits, etc.).

Given the global distribution of academies, and the diversity of nationalities and religions within them, cultural differences are evidently present. Islamic fasting for example is distinct from regular voluntary or experimental fasting (Bahammam et al., 2014) and reduced sleep duration during Ramadan fasting compared to non-fasting has been reported (Bahammam et al., 2013). Indeed, compared to Western Societies, Arab Societies tend to "have a culture associated with a lifestyle that does not promote sufficient hours of sleep each night" (Merdad et al., 2014). For example, data from Saudi Arabia indicates that $~ 30 \%$ of adolescents sleep $<5 \mathrm{~h}$ per night, with an average of $6.8 \mathrm{~h}$ in "night sleepers" and $8.5 \mathrm{~h}$ in "day sleepers." Of particular concern is that $\sim 10 \%$ of this sample demonstrated reverse sleep-wake cycles outside of Ramadan (i.e., they slept during the day; Merdad et al., 2014). Relative to The National Sleep Foundations recommendations (Hirshkowitz et al., 2015) of 9$11 \mathrm{~h}(6-13$ years $)$ and $8-10 \mathrm{~h}$ (14-17 years) sleep per night for adolescents, those of comparable ages from Greece $(6.9 \mathrm{~h}$; Lazaratou et al., 2005), Iran (7.7 h; Ghanizadeh et al., 2008), Hong Kong (7.3 h; Chung and Cheung, 2008), Israel (7.3 h; Shochat et al., 2010), and South Africa (7.3 h; Reid et al., 2002) exhibit mean sleep durations below these recommendations (Merdad et al., 2014). A plausible explanation for this could be the increase in screen time (televisions, laptops, tablets, smart phones, eReaders, etc.) and social media use (Cain and Gradisar, 2010; Shochat et al., 2010) across society (Gamble et al., 2014; Halson, 2015), particularly within adolescents (Peiro-Velert et al., 2014; Pieters et al., 2014; Hale and Guan, 2015). Social media use and associated screen time can contribute to a "fear of missing out," which can perpetuate an "on call" psychological state, evidently counterintuitive to appropriate sleep (Halson, 2015; Lister-Landman et al., 2015). Such use of technology negatively influences desired sleep parameters, subsequent alertness and attention whilst also increasing next day caffeinated beverage consumption in an attempt to acquiesce the previous night's sleep disturbance induced drowsiness, this likely negatively influences subsequent evening sleep dependent upon time of consumption (Cain and Gradisar, 2010; Gamble et al., 2014; Dimitriou et al., 2015). These issues, discussed throughout this opinion piece, regarding sleep disturbances within adolescents, discreetly, or in various combinations, function to hinder achieving the quantity and quality of sleep endorsed by The National Sleep Foundation for adolescents (Hirshkowitz et al., 2015).

Although sleep disturbances and undesired sleep-wake patterns are evident in young people across the globe, the inter- and intra-continent variation across, and between North
America (Liu et al., 2005), Asia (Chung and Cheung, 2008; Merdad et al., 2014), Europe (Loessl et al., 2008), and Australasia (Short et al., 2013) ensures a "one size fits all” solution to rectify insufficient sleep is not externally valid, with individualization, perhaps even within the same academy likely required (Fullagar and Bartlett, 2016). Indeed, this individualized solution cannot be implemented without quantification of the problem. The problem is difficult to detect through parents/guardians, since between 40\% (Meltzer et al., 2013) and 60\% (Amschler and McKenzie, 2005) of parents are unaware of their adolescents undesirable sleep patterns. Therefore, sleep monitoring in adolescent athletes should be externally valid (i.e., non-invasive and easy to implement away from a laboratory, training ground, etc.), portable (i.e., for away fixtures and training camps) whilst possessing high validity and reliability compared to polysomnography (PSG). Validation studies comparing wrist activity monitors with PSG (n.b. the gold standard for monitoring sleep) report high correlations for sleep duration (i.e., 0.84-0.90) and moderate-to-high correlations for wake time within sleep (i.e., 0.53-0.76; Kosmadopoulos et al., 2014; Sargent et al., 2015). However, existing actigraphy data in this regard is skewed toward older- and post-adolescent athletes with recent data ( $\sim 17-25$ years) seen across 5 days to 6 weeks training or competition phases (Sargent et al., 2014, 2015; Killer et al., 2015; Kölling et al., 2015b; Lastella et al., 2015a,b; Shearer et al., 2015; Dennis et al., 2016; Romyn et al., 2016), with only a single data set ( $\sim 24$ years) collected across a full season (Dennis et al., 2016). There is a paucity of season-long sleep monitoring data from school age (8-18 years) adolescent academy athletes in addition to cultural comparisons (i.e., Arab compared to Western academies). Wrist actigraphy is therefore recommended as a practically administrable tool to quantitatively monitor sleep whether the athlete is at their home, or not. Furthermore, an appropriately composed questionnaire could enrich the wrist actigraphy derived data however, there is not currently a ubiquitously adopted "sleep quality" questionnaire administered by practitioners. Practitioners, researchers and athletes should work together to develop and validate such an appropriate sleep questionnaire (validated against actigraphy) for adoption across practice, advancing recent efforts related to team sports (Kölling et al., 2015a; Fullagar et al., 2016).

A reduction in adolescent sleep has occurred over the last century (Matricciani et al., 2011). Specifically, within the past two decades, a mismatch has developed between the perception of adequate sleep and adolescents globally reported actual sleep durations (Keyes et al., 2015). Moreover, this reduction has been overtly modified by socio-economic, racial, ethnicity and religious factors (Keyes et al., 2015). The contextualized empirically informed paradigm presented within this opinion article strongly suggests there is an obligation of academies, practitioners, athletes, and their parents to ensure academic and athletic development are supported by appropriate sleep. This can only be realized if appropriate sleep monitoring (utilizing the practical methodological recommendations stated earlier) is embedded within academy programmes, and is embraced by the athlete and their support network. Implementation, adoption and athlete adherence to such monitoring is dependent upon 
appropriate interaction between medically qualified staff, athletes and practitioners, and tri-partite evidence informed education within this axis (Taylor et al., 2016). Adolescent academy athletes must be made overtly aware of the consequences of insufficient sleep on their holistic development, with education the most viable vehicle to facilitate this awareness and adherence (Burgess and Naughton, 2010). These academy sleep issues may be particularly important in the Middle East as cultural factors may result in very poor sleep (as detailed above) compared to age matched controls from other regions (Merdad et al.,

\section{REFERENCES}

Alibhai, F. J., Tsimakouridze, E. V., Reitz, C. J., Pyle, W. G., and Martino, T. A. (2015). Consequences of circadian and sleep disturbances for the cardiovascular system. Can. J. Cardiol. 31, 860-872. doi: 10.1016/j.cjca.2015.01.015

Amschler, D. H., and McKenzie, J. F. (2005). Elementary students' sleep habits and teacher observations of sleep-related problems. J. Sch. Health 75, 50-56. doi: 10.1111/j.1746-1561.2005.tb00010.x

Armstrong, N., and McManus, A. M. (2011). The Elite Young Athlete. Basel: Karger.

Baekeland, F., and Lasky, R. (1966). Exercise and sleep patterns in college athletes. Percept. Mot. Skills 23, 1203-1207. doi: 10.2466/pms.1966.23.3f.1203

Baert, S., Omey, E., Verhaest, D., and Vermeir, A. (2015). Mister sandman, bring me good marks! On the relationship between sleep quality and academic achievement. Soc. Sci. Med. 130, 91-98. doi: 10.1016/j.socscimed.2015.02.011

Bahammam, A. S., Alaseem, A. M., Alzakri, A. A., and Sharif, M. M. (2013). The effects of ramadan fasting on sleep patterns and daytime sleepiness: an objective assessment. J. Res. Med. Sci. 18, 127-131.

Bahammam, A. S., Almushailhi, K., Pandi-Perumal, S. R., and Sharif, M. M. (2014). Intermittent fasting during ramadan: does it affect sleep? J. Sleep Res. 23, 35-43. doi: 10.1111 /jsr.12076

Barker, A. R., and Armstrong, N. (2011). Exercise testing elite young athletes. Med. Sport Sci. 56, 106-125. doi: 10.1159/000320642

Barnes, J. C., and Meldrum, R. C. (2015). The impact of sleep duration on adolescent development: a genetically informed analysis of identical twin pairs. J. Youth Adolesc. 44, 489-506. doi: 10.1007/s10964-014-0137-4

Bartel, K. A., Gradisar, M., and Williamson, P. (2015). Protective and risk factors for adolescent sleep: a meta-analytic review. Sleep Med. Rev. 21, 72-85. doi: 10.1016/j.smrv.2014.08.002

Bergeron, M. F., Mountjoy, M., Armstrong, N., Chia, M., Cote, J., Emery, C. A., et al. (2015). International olympic committee consensus statement on youth athletic development. Br. J. Sports Med. 49, 843-851. doi: 10.1136/bjsports2015-094962

Boyd, C. J., Austic, E., Epstein-Ngo, Q., Veliz, P. T., and McCabe, S. E. (2015). A prospective study of adolescents' nonmedical use of anxiolytic and sleep medication. Psychol. Addict. Behav. 29, 184-191. doi: 10.1037/adb0000026

Bulbulian, R., Heaney, J. H., Leake, C. N., Sucec, A. A., and Sjoholm, N. T. (1996). The effect of sleep deprivation and exercise load on isokinetic leg strength and endurance. Eur. J. Appl. Physiol. Occup. Physiol. 73, 273-277. doi: 10.1007/BF02425487

Burgess, D. J., and Naughton, G. A. (2010). Talent development in adolescent team sports: a review. Int. J. Sports Physiol. Perform. 5, 103-116.

Cain, N., and Gradisar, M. (2010). Electronic media use and sleep in schoolaged children and adolescents: a review. Sleep Med. 11, 735-742. doi: 10.1016/j.sleep.2010.02.006

Carskadon, M. A. (2005). Sleep and circadian rhythms in children and adolescents: relevance for athletic performance of young people. Clin. Sports Med. 24, 319-328. doi: 10.1016/j.csm.2004.12.001

Chung, K. F., and Cheung, M. M. (2008). Sleep-wake patterns and sleep disturbance among hong kong chinese adolescents. Sleep 31, 185-194.

Crowley, S. J., Acebo, C., and Carskadon, M. A. (2007). Sleep, circadian rhythms, and delayed phase in adolescence. Sleep Med. 8, 602-612. doi: 10.1016/j.sleep.2006.12.002
2014). Without such a change in practice, not only are long term athletic and academic successes jeopardized, but serious pathophysiologies, health issues, risk taking behavior, and poor quality of life are all dangerously increased for the adolescent athlete (Owens J. et al., 2014).

\section{AUTHOR CONTRIBUTIONS}

LT, BC, BD, KC, PF-contributed to conceptualization, drafting, and critical appraisal of the opinion article.

Dennis, J., Dawson, B., Heasman, J., Rogalski, B., and Robey, E. (2016). Sleep patterns and injury occurrence in elite australian footballers. J. Sci. Med. Sport 19, 113-116. doi: 10.1016/j.jsams.2015.02.003

Diaz-Morales, J. F., and Escribano, C. (2015). Social jetlag, academic achievement and cognitive performance: understanding gender/sex differences. Chronobiol. Int. 32, 822-831. doi: 10.3109/07420528.2015.1041599

DiFiori, J. P., Benjamin, H. J., Brenner, J. S., Gregory, A., Jayanthi, N., Landry, G. L., et al. (2014). Overuse injuries and burnout in youth sports: a position statement from the american medical society for sports medicine. $\mathrm{Br}$. J. Sports Med. 48, 287-288. doi: 10.1136/bjsports-2013-093299

Dimitriou, D., Le Cornu Knight, F., and Milton, P. (2015). The role of environmental factors on sleep patterns and school performance in adolescents. Front. Psychol. 6:1717. doi: 10.3389/fpsyg.2015.01717

Eckerberg, B., Lowden, A., Nagai, R., and Akerstedt, T. (2012). Melatonin treatment effects on adolescent students' sleep timing and sleepiness in a placebo-controlled crossover study. Chronobiol. Int. 29, 1239-1248. doi: 10.3109/07420528.2012.719962

Escribano, C., Diaz-Morales, J. F., Delgado, P., and Collado, M. J. (2012). Morningness/eveningness and school performance among spanish adolescents: further evidence. Learn. Individ. Differ. 22, 409-413. doi: 10.1016/j.lindif.2011.12.008

Facer-Childs, E., and Brandstaetter, R. (2015). The impact of circadian phenotype and time since awakening on diurnal performance in athletes. Curr. Biol. 25, 518-522. doi: 10.1016/j.cub.2014.12.036

Franckle, R. L., Falbe, J., Gortmaker, S., Ganter, C., Taveras, E. M., Land, T., et al. (2015). Insufficient sleep among elementary and middle school students is linked with elevated soda consumption and other unhealthy dietary behaviors. Prev. Med. 74, 36-41. doi: 10.1016/j.ypmed.2015.02.007

Fullagar, H. H., and Bartlett, J. D. (2016). Time to wake up: individualising the approach to sleep promotion interventions. Br. J. Sports Med. 50, 143-144. doi: 10.1136/bjsports-2015-095759

Fullagar, H. H., Skorski, S., Duffield, R., Hammes, D., Coutts, A. J., and Meyer, T. (2015). Sleep and athletic performance: the effects of sleep loss on exercise performance, and physiological and cognitive responses to exercise. Sports Med. 45, 161-186. doi: 10.1007/s40279-014-0260-0

Fullagar, H. H. K., Duffield, R., Skorski, S., Coutts, A. J., Julian, R., and Meyer, T. (2015). Sleep and recovery in team sport: current sleep-related issues facing professional team-sport athletes. Int. J. Sports Physiol. Perform. 10, 950-957. doi: 10.1123/ijspp.2014-0565

Fullagar, H. H. K., Skorski, S., Duffield, R., Julian, R., Bartlett, J., and Meyer, T. (2016). Impaired sleep and recovery after night matches in elite football players. J. Sports Sci. doi: 10.1080/02640414.2015.1135249. [Epub ahead of print].

Gamble, A. L., D’Rozario, A. L., Bartlett, D. J., Williams, S., Bin, Y. S., Grunstein, R. R., et al. (2014). Adolescent sleep patterns and night-time technology use: Results of the australian broadcasting corporation's big sleep survey. PLoS ONE 9:e111700. doi: 10.1371/journal.pone.0111700

Ghanizadeh, A., Kianpoor, M., Rezaei, M., Rezaei, H., Moini, R., Aghakhani, K., et al. (2008). Sleep patterns and habits in high school students in iran. Ann. Gen. Psychiatry 7:5. doi: 10.1186/1744-859X-7-5

Gradisar, M., Gardner, G., and Dohnt, H. (2011). Recent worldwide sleep patterns and problems during adolescence: a review and meta-analysis of age, region, and sleep. Sleep Med. 12, 110-118. doi: 10.1016/j.sleep.2010. 11.008 
Grandner, M. A., Williams, N. J., Knutson, K. L., Roberts, D., and Jean-Louis, G. (2016). Sleep disparity, race/ethnicity, and socioeconomic position. Sleep Med. 18, 7-18. doi: 10.1016/j.sleep.2015.01.020

Hale, L., and Guan, S. (2015). Screen time and sleep among school-aged children and adolescents: a systematic literature review. Sleep Med. Rev. 21, 50-58. doi: 10.1016/j.smrv.2014.07.007

Halson, S. L. (2014). Sleep in elite athletes and nutritional interventions to enhance sleep. Sports Med. 44, 13-23. doi: 10.1007/s40279-014-0147-0

Halson, S. L. (2015). Stealing sleep: is sport or society to blame? Br. J. Sports Med. doi: 10.1136/bjsports-2015-094961. [Epub ahead of print].

Harwood, C., and Knight, C. (2009). Understanding parental stressors: an investigation of british tennis-parents. J. Sports Sci. 27, 339-351. doi: 10.1080/02640410802603871

Hirshkowitz, M., Whiton, K., Albert, S. M., Alessi, C., Bruni, O., DonCarlos, L., et al. (2015). National sleep foundation's sleep time duration recommendations: methodology and results summary. Sleep Health 1, 40-43. doi: 10.1016/j.sleh.2014.12.010

Juliff, L. E., Halson, S. L., and Peiffer, J. J. (2015). Understanding sleep disturbance in athletes prior to important competitions. J. Sci. Med. Sport 18, 13-18. doi: 10.1016/j.jsams.2014.02.007

Kaneita, Y., Ohida, T., Osaki, Y., Tanihata, T., Minowa, M., Suzuki, K., et al. (2007). Association between mental health status and sleep status among adolescents in japan: a nationwide cross-sectional survey. J. Clin. Psychiatry 68, 1426-1435. doi: 10.4088/JCP.v68n0916

Keyes, K. M., Maslowsky, J., Hamilton, A., and Schulenberg, J. (2015). The great sleep recession: changes in sleep duration among us adolescents, 1991-2012. Pediatrics 135, 460-468. doi: 10.1542/peds.2014-2707

Killer, S. C., Svendsen, I. S., Jeukendrup, A. E., and Gleeson, M. (2015). Evidence of disturbed sleep and mood state in well-trained athletes during shortterm intensified training with and without a high carbohydrate nutritional intervention. J. Sports Sci. doi: 10.1080/02640414.2015.1085589. [Epub ahead of print].

Kölling, S., Hitzschke, B., Holst, T., Ferrauti, A., Meyer, T., Pfeiffer, M., et al. (2015a). Validity of the acute recovery and stress scale: training monitoring of the german junior national field hockey team. Int. J. Sports Sci. Coach. 10, 529-542. doi: 10.1260/1747-9541.10.2-3.529

Kölling, S., Wiewelhove, T., Raeder, C., Endler, S., Ferrauti, A., Meyer, T., et al. (2015b). Sleep monitoring of a six-day microcycle in strength and highintensity training. Eur. J. Sport Sci. doi: 10.1080/17461391.2015.1041062. [Epub ahead of print].

Kosmadopoulos, A., Sargent, C., Darwent, D., Zhou, X., and Roach, G. D. (2014). Alternatives to polysomnography (psg): a validation of wrist actigraphy and a partial-psg system. Behav. Res. Methods 46, 1032-1041. doi: 10.3758/s13428013-0438-7

Lastella, M., Roach, G. D., Halson, S. L., Martin, D. T., West, N. P., and Sargent, C. (2015a). Sleep/wake behaviour of endurance cyclists before and during competition. J. Sports Sci. 33, 293-299. doi: 10.1080/02640414.2014.942690

Lastella, M., Roach, G. D., Halson, S. L., and Sargent, C. (2015b). Sleep/wake behaviours of elite athletes from individual and team sports. Eur. J. Sport Sci. 15, 94-100. doi: 10.1080/17461391.2014.932016

Lazaratou, H., Dikeos, D. G., Anagnostopoulos, D. C., Sbokou, O., and Soldatos, C. R. (2005). Sleep problems in adolescence. A study of senior high school students in greece. Eur. Child Adolesc. Psychiatry 14, 237-243. doi: 10.1007/s00787-0050460-0

Liakoni, E., Schaub, M. P., Maier, L. J., Glauser, G. V., and Liechti, M. E. (2015). The use of prescription drugs, recreational drugs, and "soft enhancers" for cognitive enhancement among swiss secondary school students. PLoS ONE 10:e141289. doi: 10.1371/journal.pone.0141289

Lister-Landman, K. M., Domoff, S. E., and Dubow, E. F. (2015). The role of compulsive texting in adolescents' academic functioning. Psychol. Pop. Media Cult. doi: 10.1037/ppm0000100. [Epub ahead of print].

Liu, X., Liu, L., Owens, J. A., and Kaplan, D. L. (2005). Sleep patterns and sleep problems among schoolchildren in the united states and china. Pediatrics 115, 241-249. doi: 10.1542/peds.2004-0815F

Lloyd, R. S., Oliver, J. L., Faigenbaum, A. D., Howard, R., De Ste Croix, M. B. A., Williams, C. A., et al. (2015a). Long-term athletic developmentpart 1: a pathway for all youth. J. Strength Cond. Res. 29, 1439-1450. doi: 10.1519/JSC.0000000000000756
Lloyd, R. S., Oliver, J. L., Faigenbaum, A. D., Howard, R., De Ste Croix, M. B. A., Williams, C. A., et al. (2015b). Long-term athletic development, part 2: barriers to success and potential solutions. J. Strength Cond. Res. 29, 1451-1464. doi: 10.1519/01.JSC.0000465424.75389.56

Loessl, B., Valerius, G., Kopasz, M., Hornyak, M., Riemann, D., and Voderholzer, U. (2008). Are adolescents chronically sleep-deprived? An investigation of sleep habits of adolescents in the southwest of germany. Child Care Health Dev. 34, 549-556. doi: 10.1111/j.1365-2214.2008.00845.x

Luke, A., Lazaro, R. M., Bergeron, M. F., Keyser, L., Benjamin, H., Brenner, J., et al. (2011). Sports-related injuries in youth athletes: is overscheduling a risk factor? Clin. J. Sport Med. 21, 307-314. doi: 10.1097/JSM.0b013 e3182218f71

Malina, R. M. (2010). Early sport specialization: roots, effectiveness, risks. Curr. Sports Med. Rep. 9, 364-371. doi: 10.1249/JSR.0b013e3181fe3166

Matricciani, L., Olds, T., and Williams, M. (2011). A review of evidence for the claim that children are sleeping less than in the past. Sleep 34, 651-659.

McCabe, S. E., and West, B. T. (2014). Medical and nonmedical use of prescription benzodiazepine anxiolytics among us high school seniors. Addict. Behav. 39, 959-964. doi: 10.1016/j.addbeh.2014.01.009

McCabe, S. E., West, B. T., Cranford, J. A., Ross-Durow, P., Young, A., Teter, C. J., et al. (2011). Medical misuse of controlled medications among adolescents. Arch. Pediatr. Adolesc. Med. 165, 729-735. doi: 10.1001/archpediatrics.2011.114

Mellman, T. A. (2006). Sleep and anxiety disorders. Psychiatr. Clin. North Am. 29, 1047-1058. doi: 10.1016/j.psc.2006.08.005

Meltzer, L. J., Avis, K. T., Biggs, S., Reynolds, A. C., Crabtree, V. M., and Bevans, K. B. (2013). The children's report of sleep patterns (crsp): a self-report measure of sleep for school-aged children. J. Clin. Sleep Med. 9, 235-245. doi: $10.5664 /$ jcsm. 2486

Merdad, R. A., Merdad, L. A., Nassif, R. A., El-Derwi, D., and Wali, S. O. (2014). Sleep habits in adolescents of saudi arabia; distinct patterns and extreme sleep schedules. Sleep Med. 15, 1370-1378. doi: 10.1016/j.sleep.2014.06.008

Milewski, M. D., Skaggs, D. L., Bishop, G. A., Pace, J. L., Ibrahim, D. A., Wren, T. A., et al. (2014). Chronic lack of sleep is associated with increased sports injuries in adolescent athletes. J. Pediatr. Orthop. 34, 129-133. doi: 10.1097/BPO.0000000000000151

Mountjoy, M., and Bergeron, M. F. (2015). Youth athletic development: aiming high while keeping it healthy, balanced and fun! Br. J. Sports Med. 49, 841-842. doi: 10.1136/bjsports-2015-094967

Mountjoy, M., Rhind, D. J. A., Tiivas, A., and Leglise, M. (2015). Safeguarding the child athlete in sport: a review, a framework and recommendations for the ioc youth athlete development model. Br. J. Sports Med. 49, 883-886. doi: 10.1136/bjsports-2015-094619

Nedelec, M., Halson, S., Abaidia, A., Ahmaidi, S., and Dupont, G. (2015a). Stress, sleep and recovery in elite soccer: a critical review of the literature. Sports Med. 45, 1387-1400. doi: 10.1007/s40279-015-0358-Z

Nedelec, M., Halson, S., Delecroix, B., Abaidia, A. E., Ahmaidi, S., and Dupont, G. (2015b). Sleep hygiene and recovery strategies in elite soccer players. Sports Med. 45, 1547-1559. doi: 10.1007/s40279-015-0377-9

Nyer, M., Farabaugh, A., Fehling, K., Soskin, D., Holt, D., Papakostas, G. I., et al. (2013). Relationship between sleep disturbance and depression, anxiety, and functioning in college students. Depress. Anxiety 30, 873-880. doi: 10.1002/da.22064

Oliver, S. J., Costa, R. J., Laing, S. J., Bilzon, J. L., and Walsh, N. P. (2009). One night of sleep deprivation decreases treadmill endurance performance. Eur. J. Appl. Physiol. 107, 155-161. doi: 10.1007/s00421-009-1103-9

Owens, J., Adolescent Sleep Working, G., and Comm, A. (2014). Insufficient sleep in adolescents and young adults: an update on causes and consequences. Pediatrics 134, E921-E932. doi: 10.1542/peds.2014-1696

Owens, J. A., Allison, M., Allison, M., Ancona, R., Barnett, S. E., Gunther, R., et al. (2014). School start times for adolescents. Pediatrics 134, 642-649. doi: 10.1542/peds.2014-1697

Papadimitriou, G. N., and Linkowski, P. (2005). Sleep disturbance in anxiety disorders. Int. Rev. Psychiatry 17, 229-236. doi: 10.1080/09540260500 104524

Peiro-Velert, C., Valencia-Peris, A., Gonzalez, L. M., Garcia-Masso, X., Serra-Ano, P., and Devis-Devis, J. (2014). Screen media usage, sleep time and academic performance in adolescents: clustering a self-organizing maps analysis. PLoS ONE 9:e99478. doi: 10.1371/journal.pone.0099478 
Pieters, D., De Valck, E., Vandekerckhoye, M., Pirrera, S., Wuyts, J., Exadaktylos, V., et al. (2014). Effects of pre-sleep media use on sleep/wake patterns and daytime functioning among adolescents: the moderating role of parental control. Behav. Sleep Med. 12, 427-443. doi: 10.1080/15402002.2012.694381

Prather, A. A., Janicki-Deverts, D., Hall, M. H., and Cohen, S. (2015). Behaviorally assessed sleep and susceptibility to the common cold. Sleep 38, 1353-1359. doi: $10.5665 /$ sleep. 4968

Reid, A., Maldonado, C. C., and Baker, F. C. (2002). Sleep behavior of south african adolescents. Sleep 25, 423-427.

Rexroat, R. (2014). NCAA National Study of Substance Use Habits of College Student-Athletes. National Collegiate Athletic Association, 1-101.

Rigg, K. K., and Ford, J. A. (2014). The misuse of benzodiazepines among adolescents: psychosocial risk factors in a national sample. Drug Alcohol Depend. 137, 137-142. doi: 10.1016/j.drugalcdep.2014.01.026

Romyn, G., Robey, E., Dimmock, J. A., Halson, S. L., and Peeling, P. (2016). Sleep, anxiety and electronic device use by athletes in the training and competition environments. Eur. J. Sport Sci. 16, 301-308. doi: 10.1080/17461391.2015. 1023221

Rutters, F., Lemmens, S. G., Adam, T. C., Bremmer, M. A., Elders, P. J., Nijpels, G., et al. (2014). Is social jetlag associated with an adverse endocrine, behavioral, and cardiovascular risk profile? J. Biol. Rhythms 29, 377-383. doi: 10.1177/0748730414550199

Sargent, C., Lastella, M., Halson, S. L., and Roach, G. D. (2014). The impact of training schedules on the sleep and fatigue of elite athletes. Chronobiol. Int. 31, 1160-1168. doi: 10.3109/07420528.2014.957306

Sargent, C., Lastella, M., Halson, S. L., and Roach, G. D. (2015). The validity of activity monitors for measuring sleep in elite athletes. J. Sci. Med. Sport. doi: 10.1016/j.jsams.2015.12.007. [Epub ahead of print].

Shearer, D. A., Jones, R. M., Kilduff, L. P., and Cook, C. J. (2015). Effects of competition on the sleep patterns of elite rugby union players. Eur. J. Sport Sci. 15, 681-686. doi: 10.1080/17461391.2015.1053419

Shochat, T., Cohen-Zion, M., and Tzischinsky, O. (2014). Functional consequences of inadequate sleep in adolescents: a systematic review. Sleep Med. Rev. 18, 75-87. doi: 10.1016/j.smrv.2013.03.005

Shochat, T., Flint-Bretler, O., and Tzischinsky, O. (2010). Sleep patterns, electronic media exposure and daytime sleep-related behaviours among israeli adolescents. Acta Paediatr. 99, 1396-1400. doi: 10.1111/j.16512227.2010.01821.x

Short, M. A., Gradisar, M., Lack, L. C., Wright, H. R., Dewald, J. F., Wolfson, A. R., et al. (2013). A cross-cultural comparison of sleep duration between U.S. and australian adolescents: the effect of school start time, parent-set bedtimes, and extracurricular load. Health Educ. Behav. 40, 323-330. doi: $10.1177 / 1090198112451266$

Sivertsen, B., Glozier, N., Harvey, A. G., and Hysing, M. (2015). Academic performance in adolescents with delayed sleep phase. Sleep Med. 16, 1084-1090. doi: 10.1016/j.sleep.2015.04.011

Skein, M., Duffield, R., Minett, G. M., Snape, A., and Murphy, A. (2013). The effect of overnight sleep deprivation after competitive rugby league matches on postmatch physiological and perceptual recovery. Int. J. Sports Physiol. Perform. 8, 556-564.
Smith, R. S., Efron, B., Mah, C. D., and Malhotra, A. (2013). The impact of circadian misalignment on athletic performance in professional football players. Sleep 36 , 1999-2001. doi: 10.5665/sleep.3248

Souissi, N., Chtourou, H., Aloui, A., Hammouda, O., Dogui, M., Chaouachi, A., et al. (2013). Effects of time-of-day and partial sleep deprivation on shortterm maximal performances of judo competitors. J. Strength Cond. Res. 27, 2473-2480. doi: 10.1519/JSC.0b013e31827f4792

Souissi, N., Sesboue, B., Gauthier, A., Larue, J., and Davenne, D. (2003). Effects of one night's sleep deprivation on anaerobic performance the following day. Eur. J. Appl. Physiol. 89, 359-366. doi: 10.1007/s00421-003-0793-7

Souissi, N., Souissi, M., Souissi, H., Chamari, K., Tabka, Z., Dogui, M., et al. (2008). Effect of time of day and partial sleep deprivation on short-term, high-power output. Chronobiol. Int. 25, 1062-1076. doi: 10.1080/07420520802 551568

Staner, L. (2003). Sleep and anxiety disorders. Dialogues Clin. Neurosci. 5, 249-258.

Taylor, L., Chrismas, B., Dascombe, B., Chamari, K., and Fowler, P. M. (2016). Sleep medication and athletic performance - the evidence for practitioners and future research directions. Front. Physiol. 7:83. doi: 10.3389/fphys.2016.00083

Thun, E., Bjorvatn, B., Flo, E., Harris, A., and Pallesen, S. (2015). Sleep, circadian rhythms, and athletic performance. Sleep Med. Rev. 23, 1-9. doi: 10.1016/j.smrv.2014.11.003

Tonetti, L., Natale, V., and Randler, C. (2015). Association between circadian preference and academic achievement: a systematic review and meta-analysis. Chronobiol. Int. 32, 792-801. doi: 10.3109/07420528.2015.1049271

Touitou, Y. (2013). Adolescent sleep misalignment: a chronic jet lag and a matter of public health. J. Physiol. Paris 107, 323-326. doi: 10.1016/j.jphysparis.2013.03.008

Van Dongen, H. P., Maislin, G., Mullington, J. M., and Dinges, D. F. (2003a). The cumulative cost of additional wakefulness: Dose-response effects on neurobehavioral functions and sleep physiology from chronic sleep restriction and total sleep deprivation. Sleep 26, 117-126.

Van Dongen, H. P. A., Rogers, N. L., and Dinges, D. F. (2003b). Sleep debt: Theoretical and empirical issues. Sleep Biol. Rhythms 1, 5-13. doi: 10.1046/j.1446-9235.2003.00006.x

Wolfson, A. R., Spaulding, N. L., Dandrow, C., and Baroni, E. M. (2007). Middle school start times: the importance of a good night's sleep for young adolescents. Behav. Sleep Med. 5, 194-209. doi: 10.1080/154020007012 63809

Conflict of Interest Statement: The authors declare that the research was conducted in the absence of any commercial or financial relationships that could be construed as a potential conflict of interest.

Copyright (c) 2016 Taylor, Chrismas, Dascombe, Chamari and Fowler. This is an open-access article distributed under the terms of the Creative Commons Attribution License (CC BY). The use, distribution or reproduction in other forums is permitted, provided the original author(s) or licensor are credited and that the original publication in this journal is cited, in accordance with accepted academic practice. No use, distribution or reproduction is permitted which does not comply with these terms. 